director of political and military affairs, pointed to extracts from an East German military manual printed in the report which gives details of how toxin weapons might be used, pointing out that the suggested circumstances were similar to those reported in South-East Asia.

"We think Laos, Cambodia (Kampuchea) and Afghanistan are 'proving grounds' for testing the chemical and biological weapons capability of the Soviet Army", Mr Burt said. "In all three countries there is strong local resistance which stands in the way of Soviet objectives, and where the conventional use of troops would be very costly."

Department officials refused, on national security grounds, to say how all the various samples and reports had been obtained. In analysing the samples, $\mathrm{Mr}$ Burt said, the department had received technical cooperation from the British government as well as the Japanese.

Disputing press reports that tricothecenes were not powerful enough to be a useful tactical weapon, Dr Sharon Watson of the Army Surgeon General's Office said that experiments carried out at the army's testing centre in Fort Detrick, Maryland, had shown that haemorrhaging, caused by a severe impairment of blood-clotting, could occur at very low exposure levels. Experiments had shown that for a 70 kilogramme man the LD50 dose could be as low as $\mathbf{3 5}$ milligrammes.

Furthermore, Dr Watson said, the army had reason to believe that a crude extract from Fusarium was being used, which could be more toxic than the purified form. Referring to the broader implications of the charges being made against the Soviet Union, Mr Burt said that the evidence for the use of toxins in South-East Asia illustrated that one of the major flaws in the 1972 convention banning the use of toxins in war was that it contained no provision for verifying compliance.

David Dickson

\section{Information technology}

\section{Cables coming}

If Britain does not prepare to accept cable information systems now, then it may as well not bother at all. That is the message contained in a report to the Cabinet Office which was prepared by the government's Information Technology Advisory Panel and published earlier this week. Such is the urgency perceived by the panel of the need to provide cable television for British viewers that the report urges the government to make its intentions clear even before fully resolving some thorny problems such as regulation and licensing of the programmes that can be transmitted.

The government seems set to take on board the gist of the report's recommendations which include announcements of broad policy by mid-1982, regulatory arrangements by early 1983 and the formulation of technical standards for the cable network by the end of this year. Civil servants in several government departments are now trying to work out the details. Thus the more leisurely approach to cable television which was envisaged as recently as early last year, when the Home Secretary approved 13 pilot schemes, looks like being abandoned. Decisions must now be taken, according to the report, before the results of those schemes can be known, in order to prevent overseas companies from hastening the decline of the British cable television industry.

The chief interest in cable systems is said to lie in their potential for linking new information technologies. But the panel believes that large numbers of users will only be attracted to the system quickly if it starts by offering a wide choice of television programmes. Mr Charles Read, chairman of the panel, hopes that programme providers can be licensed within existing legislation, which gives the Home Secretary wide powers of discretion.

Public fears about the quality of broadcast programmes, which traditionally have been tightly controlled in Britain, may not be so easily allayed. This problem will soon be tackled by Lord Hunt, formerly secretary to the Cabinet, who is to hold an urgent inquiry into the likely effects of cable television on the public broadcasting system.

Precise specifications for the cable system have yet to be established. But the panel's report envisages series of local networks, initially in large cities, that would offer broad bandwidth communications capable of carrying 15-24 channels. British packet-switching technology that would allow cable to individual homes to be of lower bandwidth than that on trunk lines is favoured.

The cost of cabling half the British population, according to the report, would be about $£ 2,500$ million, all of which would have to be found by the private sector, which apparently is eager to put up the money.

Costs, says the report, might be minimized if British Telecom ducts were used for laying the new cable. Local networks could, for example, be interconnected via its own telephone network. And as private broad bandwidth cables may well be installed before its own network is upgraded, the company would be wise to consider putting some of its own services, such as Prestel, onto the new cables.

While welcoming British Telecom's interest in the new cables systems, the panel's report is nevertheless cautious about the extent of the company's involvement. It is particularly keen, for example, that British Telecom should not dictate the standards for the new networks, presumably fearing that the company would be too restrictive and cause unnecessary delay.

Judy Redfearn

\section{Neuroscience moves}

\section{New York}

The Neurosciences Research Program, the seemingly clubby survival from the time when it seemed necessary, twenty years ago, to persuade people that neurobiology was interesting, is in the throes of moving from Boston to New York. At the same time, it has been given a new image and an income that it can call its own.

The organization was begun in 1962 by Professor Francis O. Schmitt, largely to proselytize on behalf of the neurosciences. Since then it has been housed in a replica of a French chateau 15 miles from Boston, and has been best known for its periodic small workshops (up to six a year) on various aspects of neurobiology. Now, however, the organization has negotiated a lease with Rockefeller University that will allow it to house not merely its administrative staff but a new institute, called the Neurosciences Institute, intended to provide up to half a dozen relatively senior people in the field (and perhaps as many junior colleagues) with an opportunity for conceptual (as distinct from experimental) work for short periods of time.

Both parties to the lease now signed are anxious to emphasize that the Neurosciences Research Foundation, by becoming a tenant of the university, will not become a part of it. The foundation will in future finance both the Neurosciences Institute and the Neurosciences Research Program from an income that appears to exceed $\$ 500,000$ a year.

In the move from Boston to New York, some care seems to have been taken to broaden representation in the management of the enterprise, with the result that it is often hard to tell who will do what. The director of the Neurosciences Research Program from the president of the foundation) is $\mathrm{Dr}$ Vernon B. Mountcastle, President of Johns Hopkins University. Dr W. Maxwell Cowan of the Salk Institute is the chairman of the Scientific Advisory Committee of the programme, but there is also a "scientific" chairman, Dr Gerald M. Edelman of Rockefeller University (who is also the director of the Neurosciences Institute).

Representation of the Salk Institute through Dr Cowan, is said to mark the plan that both the Neurosciences Research Program and the institute will be peripatetic, migrating en masse to the west coast for the summer months. Edelman hopes that the first of these summer programmes will take place this year, although formal arrangements with the Salk Institute have not yet been completed. 